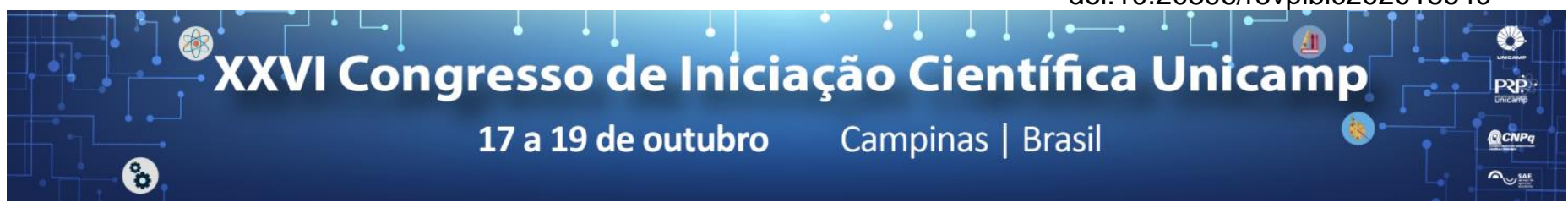

\title{
Subsídios para Criação de Zonas de Baixa Emissão em Campinas
}

\section{Giulia Dantas Barreto*, Flávia L. Consoni.}

\section{Resumo}

A LEZ (Low Emission Zone) é uma estratégia que está sendo adotada e implementada por diversos países da Europa para controlar a emissão de poluentes. Operacionalmente, essas áreas apresentam algum tipo de restrição à circulação de veículos a combustão interna que se utilizam de combustíveis fósseis. Essa pesquisa aborda e experiencia das LEZs na Itália, com enfoque nas zonas de baixa emissão de quatro cidades: Milão, Palermo, Roma e Nápoles.

\section{Palavras-chave:}

Zonas de Baixa Emissão, Transporte de Baixa Emissão, Cidades Italianas.

\section{Introdução}

As Zonas de Baixa Emissão (LEZ) são estratégias que estão sendo amplamente difundidas há vários anos, principalmente em países da Europa, com o intuito de diminuir a emissão de gases poluentes e de efeito estufa (GEE). A Itália é o país europeu com o maior número de LEZ, com mais de 100 no total, seguida da Alemanha com cerca de 70 .

Esta pesquisa buscou compreender os motivadores das LEZ em cidades italianas, como foi implementada, orientações para seu funcionamento, críticas e vantagens. A metodologia consistiu em revisão de literatura e trabalho de campo em algumas cidades italianas no ano de 2017, com entrevistas e observação acerca do funcionamento das LEZ.

\section{Resultados e Discussão}

As LEZ começaram a ser implantadas na década de 1990; um dos países pioneiros foi a Suécia, seguido pela cidade de Londres e outras localidades europeias. Apesar de cada nação possuir uma variação nas regras de entrada de veículos nessas zonas, todas têm um objetivo comum, que consiste na redução da emissão dos GEE.

Muitos benefícios foram atingidos a partir das LEZ, tais como a melhoria da saúde da população devido à diminuição de poluição e materiais particulados tais como o PM10 (partículas inaláveis com diâmetro menor que 10 microns), que podem ocasionar problemas respiratórios e cardiovasculares.

No caso específico da Itália, além dos objetivos citados acima, as LEZ também visam a preservação e maior controle dos centros históricos das cidades, já que são locais que precisam de um cuidado especial; a arrecadação de verba por meio das taxas cobradas para circular nas LEZ é direcionada a este proposito. A vigilância é feita por meio de câmeras localizadas na entrada dessas zonas, onde apenas certas categorias de veículos e pessoas estão autorizadas a passar sem o pagamento de taxas (pedágio). No caso de infrações, há a aplicação de uma multa.

Muitas cidades italianas possuem uma ou mais LEZ, com variações nas normas entre elas. Neste projeto foram abordadas em detalhes quatro cidades: Milão, Palermo, Roma e Nápoles.
Tabela 1. Número das LEZ na Europa (2014)

\begin{tabular}{|l|c|}
\hline \multicolumn{1}{|c|}{ PAÍSES } & № de LEZs \\
\hline ALEMANHA & $\sim 70$ \\
\hline DINAMARCA & 6 \\
\hline SUÉCIA & 8 \\
\hline PAÍSES BAIXOS & 13 \\
\hline ÁUSTRIA & 3 \\
\hline ITÁLIA & $\sim 92^{\star}$ \\
\hline INGLATERRA & 3 \\
\hline PORTUGAL & 1 \\
\hline
\end{tabular}

\section{Conclusões}

Através deste projeto é possível visualizar o quão positivas são as vantagens trazidas pelas LEZ, incluindo melhorias na saúde da população local e incentivos a novas e melhores tecnologias, como por exemplo, carros movidos a energia limpa e de baixa emissão.

A experiência das LEZ pode vir a ser uma estratégia para orientar a administração do espaço urbano em grandes cidades brasileiras, visando a melhoria da qualidade do ar e a circulação de veículos e de pessoas.

${ }^{1}$ LEZ da região da Lombardia foram contadas como uma unica zona. Elaborado pela Giulia Dantas Barreto. Fonte: adaptado de HOLMAN, C; HARRISON, R; QUEROL, X. Review of the efficacy of low emission zones to improve urban air quality in European cities. Inglaterra: Elsevier, 2015. Atmospheric Environment 111. Páginas 161 - 169.

BRAS, H. S. A. Avaliação dos benefícios da implementação de Zonas de Baixa Emissão Reduzidas em Lisboa. Faculdade de Ciências e Tecnologia da Universidade Nova de Lisboa, 2012

CUSTODIO, R; SILVA, F. N; MARTINS, H. Low Emission Zone: Lisbon's Experience. Journal of Traffic and Logistics Engineering Vol. 2, 2014.

HOLMAN, C; HARRISON, R; QUEROL, X. Review of the efficacy of low emission zones to improve urban air quality in European cities. Inglaterra: Elsevier, 2015. Atmospheric Environment 111. Páginas 161 - 169. 